\title{
O MODO DE RELAÇÃO DO SURDO COM A LÍNGUA MATERNA E LÍNGUA ESCRITA
}

\author{
Prof. Dr. Lucimar Bizio ${ }^{1}$
}

\section{RESUMO}

Este artigo tece considerações sobre a aquisição da língua materna, pelo surdo, e sobre como esta questão foi e tem sido tratada teoricamente até a atualidade. Para tanto, alguns autores foram selecionados com o propósito de falarem a respeito do assunto. Isso porque, para encaminhar a reflexão sobre o tema em questão, foi necessário desnaturalizar termos que circulam livremente no campo dos estudos sobre a surdez. Entre eles, destaca-se o de língua materna, L1 e L2, uma vez que, na abordagem bilinguista, entende-se a Língua de Sinais como L1, enquanto a escrita do português é considerada como segunda língua - L.2. Foram abordadas as possibilidades de contribuição do diálogo com a Linguística e também com a Psicanálise, com vistas a considerar a singularidade do surdo.

Palavras-chave: escrita do surdo; língua materna; primeira língua; segunda língua.

\begin{abstract}
This article discusses the acquisition of the mother tongue by the deaf and how this issue has been theoretically approached to date. To this end, some authors were selected aiming at denaturalizing terms and concepts that circulate freely in the field of studies on deafness. Among them, mother tongue, L1 and L2 stand out considering that in the bilingual approach, sign language is understood as an L1, while written Portuguese is considered a second language - L2. We touch the possibilities of dialogue between Linguistics and also Psychoanalysis, putting into perspective the singularity of the deaf.

Key-words: deaf person writing; mother tongue; first language; second language.
\end{abstract}

\section{INTRODUÇÃO}

A Língua de Sinais Brasileira (LIBRAS), aprovada pela Lei no 10.436, de 24 de abril de 2002, regulamentada pelo Decreto 5.626/05, vive um momento muito comum em nosso sistema educacional: o modismo. O fato de o assunto ter sido tema de redação no Exame Nacional do Ensino Médio (ENEM) em 2017 e o atual presidente, Jair Bolsonaro, ter dado ênfase a essa língua em sua campanha eleitoral, com a participação de sua esposa, especialmente na cerimônia da posse presidencial, chamou a atenção do brasileiro para o assunto, com ênfase menor para as questões do surdo enquanto cidadão, aluno e sujeito.

\footnotetext{
${ }^{1}$ Doutor em Linguística Aplicada pela PUC-SP, Professor de Língua Portuguesa para Surdos, Libras, no Centro Universitário Assunção - Unifai e no Instituto Federal São Paulo (IFSP) - Campus Votuporanga.
} 
A eleição do tema deste artigo teve origem em situações emergentes nas práticas em sala de aula, não movido pela empolgação momentânea com que o assunto é tratado no momento. Há muitos anos, venho me dedicando ao ensino de língua portuguesa para alunos surdos, que frequentam escola especial. A enorme dificuldade encontrada por esses alunos, observada ao longo de minha trajetória como docente, justifica as inquietações que mobilizaram o desejo de abordar a questão da escrita de surdos no contexto escolar.

O modo como cada surdo se expressa por escrito e como captura as informações que lhe são transmitidas pela fala é complexo e singular. Uma análise superficial da escrita de alunos surdos, considerando apenas o cenário brasileiro, revela que eles parecem claudicar entre duas línguas: a de sinais e o português escrito/oral.

O modo de entrada do surdo no universo da escrita tem sido objeto de atenção de um grande número de pesquisadores. A literatura da área revela que se trata de um tema amplo e controverso que atrai estudiosos de perspectivas teóricas distintas, que visam decifrar a trajetória enigmática de sujeitos que, em função da privação sensorial, chegam à escrita por caminhos tortuosos.

A ideia pressuposta não é somente de que se possa transferir conhecimento da primeira língua para a segunda, mas sim de que haja um processo paralelo de aquisição e aprendizagem de ambas.

Considerando a perspectiva teórica assumida em minha trajetória de estudo, coloco as seguintes questões: como pensar nas crianças cujo contato com a língua de sinais é tardia e muitas vezes apenas no universo escolar? Seria possível imaginar que elas passariam um longo período fora do universo simbólico? Como entender que elas sejam "estrangeiras” para seus próprios pais? Na realidade, percebi que, no campo da surdez, raros são os estudos que interrogam o que é uma língua, quais as relações entre sujeito e linguagem, quais os efeitos causados pela surdez na estruturação subjetiva dessas crianças e como se articulam fala/sinais/escrita para elas. Tais questões foram tematizadas, embora merecessem verticalização, especialmente considerando a envergadura de cada uma delas.

A ideia é a de que, caso não houvesse uma perda auditiva, a linguagem seria diretamente acessível ou possível de ser ensinada (tornada acessível) à medida que se assume que a linguagem é naturalmente transmissível na ausência de um déficit sensorial, como assinala Andrade (2003) ao criticar a posição de que: "A linguagem é naturalmente apreendida por um sujeito dotado de capacidades perceptuais e cognitivas" (ANDRADE, op. cit., p. 119). A autora diz, nesse enquadre, que a privação auditiva parece ser a única barreira para que a criança surda adquira linguagem em um processo de ensino-aprendizagem.

O trabalho de Cerqueira (2006) aponta para a necessidade de fazer a distinção entre ouvir e escutar':

Acredito ser necessário fazer uma distinção entre ouvir e escutar, entre organismo e corpo. Ouvir "é um fenômeno fisiológico", e escutar "é mais que isso - ele envolve

\footnotetext{
${ }^{2}$ Sobre isso, ver também Arantes (1997).
} 
'interpretação'- é um 'fenômeno linguístico'." A escuta nos remete ao sujeito, à linguagem e seus efeitos de sentido. A psicanálise nos permite pensar em um corpo como efeito de linguagem, ou como propõe De Lemos, capturado pelo funcionamento da linguagem. (CERQUEIRA, 2006, p.11)

O que se apaga, ao eleger a acessibilidade como condição necessária e suficiente para aquisição de linguagem, são exatamente os mistérios envolvidos na enigmática e complexa passagem de infans a falante, questão ainda mais complexa quando a surdez está em jogo. A própria heterogeneidade na relação do surdo com a linguagem deveria interrogar pesquisadores e suspender a naturalidade com que se pensa a aquisição da linguagem.

Entendo que, a partir de uma discussão sobre as contribuições de uma Linguística afetada pela Psicanálise, é possível colocar em pauta questões relacionadas à língua/fala/escrita, bem como aos sinais, e contribuir para um novo caminho nos estudos relativos ao ensino de Língua Portuguesa para alunos surdos. Não basta discutir a escrita como segunda língua (L2) e relacioná-la à língua de sinais, como se a escrita fosse uma mera forma de representação.

Desse modo, a escrita é sempre entendida como um objeto a ser aprendido/apreendido; seu papel é secundário em relação ao papel da fala e, também, ao papel dos sinais aos quais cabe a ela representar. Em outras palavras, sustenta-se a hipótese de que a escrita é um sistema que está subordinado à fala ou a língua de sinais. Há complexidade envolvida na relação fala/língua de sinais/ escrita, mas acompanho Guadagnoli (2007, p.56) quando afirma que: “Oralidade, escrita, gesto não são entidades autônomas e se o fossem, não poderiam ser relacionadas entre si: há um funcionamento em jogo - o da linguagem". Assim, na concepção aqui adotada, o que articula as diferentes modalidades de língua é o funcionamento da Língua, a la langue de Saussure.

Entende-se, neste texto, que não é a criança quem realiza uma apropriação da linguagem pela via da percepção, mas, acompanhando o pensamento de Claudia de Lemos (1982, 2002), parto da ideia de que a criança é capturada numa estrutura de três polos: o do sujeito, o da língua e o do Outro, entendido aqui não como socius fora da linguagem, como se vê frequentemente nas discussões pedagógicas mas, sim, como instância do funcionamento da língua constituída. A partir dessa concepção, o Projeto Aquisição, Patologias e Clínica de Linguagem, PUCSP, do qual faço parte, entende que não podemos esquecer que a relação criança-linguagem é enigmática, imprevisível e singular, ou seja, determina o modo de relação do sujeito se estruturar na linguagem. É dessa perspectiva que pretendo encaminhar minha tese.

Importante, também, no encaminhamento dessa discussão, são as contribuições de Borges ${ }^{3}$ (2006), autora que subverte a concepção corrente de que a escrita é representação da fala. Vale lembrar que para Borges (2006, p.131) "reconhecer o funcionamento da língua possibilita que as investigações sobre a aquisição da escrita não mais reduzem à relação dual oralidade sinais/escrita, mas sobre a relação triádica oralidade/escrita/língua." (grifos meus). Reduzir esse processo a uma relação que exclui a

${ }^{3}$ O livro de Sonia Borges (2006) é resultado de sua tese defendida em 1995, na PUCSP. 
Língua, isto é, a uma relação dual, implica não só a dicotomização dessas formas: linguagem oral ou de sinais e escrita, "como a substancialização, de modo que a linguagem oral é tomada como referente, e a escrita, como referência, numa relação que é da ordem do signo" (op.cit).

Penso que, de fato, a relação sujeito-objeto, tão cara aos aportes cognitivistas deva ser abandonada por uma relação triádica: tanto para abordar a fala quanto a escrita ou os sinais. O fato das diferentes modalidades poderem se afetar mutuamente é um aspecto muito importante que não pode ser desconsiderado nos estudos sobre a escrita, especialmente quando a surdez está em questão. É necessário reconhecer que "as modalidades" sejam diferentes entre si e, ao mesmo tempo, que pertençam a um mesmo domínio" (op. cit). Desse modo, a escrita deixa de ser vista como representação de um estado interno e passa a ser entendida como efeito da relação do sujeito com a linguagem.

Entendo que o olhar de um pesquisador deve estar direcionado às condições efetivas de uso da linguagem, considerando suas manifestações singulares e as condições de produção e não apenas focalizar um produto acabado. Desse modo, será possível apreender como esses sujeitos se articulam na constituição do texto escrito e, com isso, iluminar uma hipótese relativa ao modo como o surdo entra no universo gráfico. Isto é, como gesto e fala se articulam com a escrita. A perspectiva teórica que sustenta essa reflexão permite acolher, a partir do universal do funcionamento da língua, também o singular, o heterogêneo, isto é, trata-se de uma abordagem que ultrapassa o limite da descrição da linguagem enquanto falta, pois se entende que os "erros" são, muitas vezes, indícios de uma posição singular do sujeito na linguagem.

O trabalho de Carvalho (2006), ao abordar o erro em Aquisição de Linguagem, seguindo os passos de De Lemos (2014), especialmente ao abordar a questão relativamente ao que significa "saber a língua" e o "saber da língua", discute a posição do investigador e sua relação com a teoria: “ [...] trata-se de uma relação que situa o investigador em um ponto de cruzamento entre esses dois 'saberes', trazendo questões peculiares quando essa investigação tem lugar em Aquisição de Linguagem” (CARVALHO, 2006, p.63).

\section{ALGUMAS PALAVRAS SOBRE A TEORIA}

A estruturação subjetiva e estruturação da linguagem são processos solidários. Assim, vir a ser falante não é tarefa simples pois, como afirma De Lemos, a captura por um funcionamento linguístico implica conflito, "conflito a esperar do embate entre heterogêneos, entre - corpo e linguagem, corpolinguagem - e da posição da criança como objeto do desejo do Outro materno" (2014, p.122). Quando a surdez está em causa temos ainda uma situação mais complexa, tanto em função da privação sensorial quanto através dos efeitos que ela pode provocar no imaginário materno e, consequentemente, na estruturação do laço mãe-criança.

Revista Lumen, v. 4, $\mathrm{n}^{\mathrm{o}}$ 7, Jan./Jun. - 2019 - ISSN: 2447-8717 
O Grupo de Pesquisa, ao qual se filia este trabalho, tem na sua origem uma relação estreita com a Proposta Interacionista em Aquisição de Linguagem conforme proposta por De Lemos que, segundo entendo, permite discutir os modos de presença do surdo na escrita.

O encaminhamento deste artigo tem como fundamento o empreendimento teórico de Cláudia de Lemos, o Interacionismo Brasileiro. Em 1992, a partir da revisão do próprio trabalho, propõe um modo de entendimento da Aquisição da Linguagem que, pelo efeito da aproximação à Psicanálise de Jacques Lacan e à leitura original que esse autor empreendeu do estruturalismo europeu (Saussure e Jakobson), pode ganhar uma direção radicalmente distinta dos trabalhos da área: o encontro com a Psicanálise permitiu articular língua-fala-falante.

Trata-se de uma proposta que se distingue de outros interacionismo ${ }^{4}$ porque, entre a criança e o Outro, De Lemos interpõe um terceiro elemento - a língua - e a relação passa a ser triádica. Entendese que a relação não é estritamente com o outro, mas com sua fala e, nela, é suposta a língua; com isso, Outro é definido como “instância do funcionamento linguístico discursivo”. Em outras palavras, a língua - la langue - está no centro da teorização sobre a Aquisição da Linguagem. São mecanismos linguísticos que passam a responder, também, pela subjetivação.

Nas palavras da autora, "a criança é confrontada com a fala do Outro materno primordial, que a significa segundo seu desejo inconsciente, o que a privará de seu ser para fazê-la humana, ser de linguagem" (DE LEMOS, 2014, p.868); assim, a criança é, então, capturada pelos "mecanismos do significante" a que estará para sempre presa (ibidem, p.959).

A sustentação teórica deste trabalho, entretanto, deve-se aos desdobramentos teóricos empreendidos no campo da escrita por Borges e também por Lier-DeVitto no que se refere às Patologias e à Clínica de Linguagem.

O Interacionismo em Aquisição de Linguagem, de Claudia de Lemos (1992) pôde conquistar outros campos.

A originalidade da reflexão de Cláudia de Lemos não ficou restrita a questões relativas à fala da criança. Ela não só proliferou em pesquisas sobre o assunto, como os artigos neste livro testemunham, como também ultrapassou esse domínio. Por ter desenvolvido uma reflexão sobre a linguagem (língua e fala) e sobre o sujeito (sua relação à fala própria e do outro - e à língua), a empiria foi ampliada, uma vez que a relação estrutural criança-língua-fala pôde ser lida como relação sujeito-língua-fala. Trata-se, portanto, de uma arquitetura teórica aberta à possibilidade de contemplar heterogeneidades e questões singulares por elas suscitadas. Entre essas heterogeneidades estão às falas sintomáticas. Necessário, então, é sustentar diferenças e pressionar as possibilidades de rendimento do espaço teórico. (LIER-DeVITTO e ARANTES, 2006, p:12).

A leitura vigorosa de Lier-DeVitto permitiu a ela voltar-se para fala e escrita de pacientes que frequentavam a clínica fonoaudiológica. Essa autora (1997), convocada pelo enigma das patologias de

\footnotetext{
${ }^{4}$ Ver Lier-DeVitto e Carvalho 2008
} 
linguagem e tocada pela ausência de diálogo teórico entre a Fonoaudiologia e a Linguística, propôs e passou a coordenar um Projeto Integrado (CNPq 522002/-97-8) - que originou Grupo de Pesquisa LAEL-CNPq ${ }^{5}$. Deste Projeto, tem participado tanto fonoaudiólogos quanto professores da Área da Educação, todos com formação em Linguística ${ }^{6}$. Lier-DeVitto entendeu que:

"não seria qualquer teoria da Linguística com que se poderia dialogar [para abordar a fala e a escrita de pacientes fonoaudiológicos] - haveria de ser com uma em que "interação", "outro" e "erro" fossem proposições problemáticas" (LIER-DeVITTO, 2005, p.144).

Buscava com isso dar sustentação teórica a uma prática clínica. Propôs-se, assim, a revisitar "as noções de interação; mudança; erro; falante e outro; heterogeneidade e interpretação" (PIRES, 2015, p.54, grifo da autora), considerando a especificidade do objeto em questão.

Lier-DeVitto e Andrade (2008) propõem uma abordagem dos erros na escrita de crianças com dificuldades na leitura e na escrita que implica a incidência do funcionamento da língua. Elas partem da bipótese "indeterminação na escrita de crianças" (LIER-DeVITTO \& ANDRADE, 2008, p. 55) e implicam o jogo significante, que obriga que se reconheça o fato de que "unidades são efeitos de relações" (SAUSSURE, 2006). Isto é, unidades não são elementos "em si", como suposto no "acordo percepção-cognição" (LIER-DeVITTO \& ANDRADE, 2008, p. 56). Elas afirmam que "as entidades concretas da língua não se apresentam por si mesmas à nossa observação" [...] são delimitadas "pelo aspecto do valor" (SAUSSURE, 1916, p. 127-8).

Pesquisadores do grupo de Pesquisa Aquisição, Patologias e Clínica de Linguagem voltaram-se também para o campo da Educação. Santos (2008) e Pires (2015) focalizaram os alunos que cursam o Ensino Fundamental e não chegam a uma escrita legível; tocadas pelo Interacionismo e pela Psicanálise, abordam a questão a escrita de modo original. Santos (2008) defende a hipótese de que os problemas de crianças ao longo do processo de alfabetização estão relacionados à "resistência de um saber inconsciente no processo de construção de conhecimento” (SANTOS, 2008). Pires, por sua vez, volta-se para os efeitos da escrita de alunos que "fracassam" e interroga: "O 'fracasso' é do aluno, do professor ou da Escola?" (PIRES, 2015, p.72).

Bizio (2008) e Zajac (2011) também trazem questões do campo da Educação, e exploram a relação do sujeito surdo com a escrita. O primeiro busca, no Interacionismo e na Clínica de Linguagem, uma ancoragem teórica para entender a escrita do surdo não como déficit, mas sim como efeito possível do funcionamento da língua, o que se opõe à literatura do campo da Educação de Surdos.

5 Desde 2002, o Grupo de Pesquisa Aquisição, Patologias e Clínica de Linguagem é liderado por Lier-DeVitto e Lúcia Arantes no LAEL-PUC_SP. 6 São pesquisadoras com uma participação especial no Grupo de Pesquisa: Suzana Carielo da Fonseca, Lúcia Arantes, Lourdes Andrade, Rosana Landi, Luciana Carnevale; Daniela Spina-deCarvalho, Milena Faria e, depois, Juliana Marcolino Galli e Melissa Catrini.

8 Ver Lier-DeVitto, 1995.

Revista Lumen, v. 4, no 7, Jan./Jun. - 2019 - ISSN: 2447-8717 
Zajac (2011), por sua vez, diante das questões teóricas levantadas pelo Interacionismo e a Psicanálise, faz uma reflexão sobre a estruturação do surdo como sujeito. A autora também circula pela escrita do surdo e faz uma afirmação de que a escola atribui as dificuldades apresentadas na escrita do surdo "como resultado de problemas metodológicos ou da falta de fluência dos professores na LIBRAS (Língua Brasileira de Sinais)" (ZAJAC, 2011, p.14). Destaca que a falta de um olhar diferenciado sobre a escrita do surdo reside, principalmente, pelo fato do sujeito ser colocado à margem da discussão. Conclui, desse modo que: "não há uma escrita de surdos, e, sim, o surdo na escrita" (ZAJAC, 2011, p. 19).

Os pesquisadores do Bilinguismo para surdo aceitam e assumem a surdez como marca de diferença e não como déficit a ser superado. O reconhecimento de que há um limite orgânico que não pode ser ultrapassado é importante, pois se trata de uma inscrição no corpo e que afeta de modo indelével a relação deste sujeito com a linguagem. Porém, acompanho a reflexão de Cerqueira (2006) quando ela aponta o quanto é complexo "relacionar a patologia de um organismo a uma língua, a uma cultura". (CERQUEIRA, 2006, p.4). Ela acompanha as ideias de Saussure, que considera um erro "ver na língua um atributo, não mais da nação, mas da raça, ao mesmo título que a cor da pele ou a forma da cabeça." SAUSSURE (1916, p.221), ao que Cerqueira acrescenta o grau de audição.

Pensar em uma língua como um atributo, diz ela, "como característica de quem tem uma patologia orgânica parece complicado" (op.cit. p.4). Atribuir a uma raça a cor da pele, a traços biológicos uma cultura ou uma língua traz complicações político-ideológicas.

Saussure (1916) afirma que: "Embora a língua não forneça muitas informações precisas e autênticas acerca dos costumes e instituições do povo que a usa, servirá ao menos para caracterizar o tipo mental do grupo social que fala?" (SAUSSURE, op. cit., p.261). Cerqueira considera esse um ponto fundamental para que se estabeleça um diálogo com o Bilinguismo. É comum encontrar na literatura relativa a essa corrente de pensamento que a língua de sinais reflete uma forma de pensar, reflete 'a identidade' do surdo. Cerqueira (2006) destaca que, para Saussure, "é opinião geralmente aceita a de que uma língua reflete o caráter psicológico de uma nação; uma objeção bastante grave se opõe, entretanto, a tal modo de ver; um procedimento linguístico não está necessariamente determinado por causas psíquicas" (SAUSSURE, 1916, p.266,).

Como coloca Saussure, a língua "não está sujeita diretamente ao espírito dos que falam" (SAUSSURE, op. cit., p. 268), ela não reflete uma forma de pensar, e nada revela a respeito do falante. Ou ,como afirma Cerqueira, um "procedimento linguístico" nada revela sobre a "mentalidade" do falante. Neste sentido, acompanho a pesquisadora pois, de fato, "não parece que 'o Surdo' “decida" pela língua de sinais porque esta "reflete a sua forma de pensar". A língua nada nos revela em relação à raça, filiação, relações sociais, costumes, instituições, etc.” (CERQUEIRA, 2006, p.47). As questões trazidas por Cerqueira são fundamentais para desnaturalizar uma série de afirmações sobre a língua de sinais, que não enfrentam a complexidade envolvida na discussão sobre a natureza das línguas particulares e da relação que elas entretêm com a Língua, conforme definida por Saussure.

Revista Lumen, v. 4, no 7, Jan./Jun. - 2019 - ISSN: 2447-8717 
Lima (2004) levanta indagações sobre o que significa falar em bilinguismo, que implica transitar em duas línguas simultaneamente. Ainda assim, a ideia sustentada por essa proposta é de que a língua de sinais seria a língua materna do surdo e que o português a segunda língua. A ideia central é de que todo surdo deve ser bilíngue, sendo a LIBRAS sua língua materna, dado que esta é a "natural" dos surdos, e como segunda língua, a oficial do seu país. Entretanto, é preciso indagar qual o conceito de língua materna que sustenta tal afirmação, como assinala Lima (2004):

Se se toma por base que língua materna é a primeira língua aprendida por uma pessoa na infância, geralmente a de sua mãe, ou ainda, a primeira língua que o indivíduo aprende, em geral ligada ao seu ambiente, os surdos filhos de pais ouvintes não têm a língua de sinais como materna. Na verdade, a primeira língua a que essas crianças são expostas é a língua oral, uma vez que seus pais são usuários dessa língua. A língua de sinais é a língua materna, sim, de surdos filhos de pais surdos, ou, de ouvintes filhos de pais surdos. (p.44).

Lima (2004) não discute a relevância da língua de sinais na educação do surdo, mas interroga a retórica presente nos argumentos daqueles que defendem a educação bilíngue, pois há uma naturalização relativa à aquisição da língua de sinais como língua materna, e que faz crer que a única dificuldade diga respeito à aquisição da segunda língua.

As considerações que se relacionam com a educação bilíngue para o surdo não mudam muito, o que significa que a contenda gira em torno, quase sempre, da aquisição da língua materna, a qual gerará o substrato necessário à aquisição da segunda língua. A adição dessas duas parcelas L1 + L2 (língua de sinais e português) resultará, então, no surdo bilíngue. O problema é que quase ninguém pergunta: como obter a segunda parcela (L2) sem a adição da primeira parcela (L1)? Como obter a soma sem uma das parcelas (L1 e L2)? Ou ainda, sem as duas? (LIMA, 2004. p.47)

Não se pode refutar a ideia de que a educação de surdos é complexa e enfrenta diversos problemas, de vários âmbitos: políticos, educativos, linguísticos, capacitação de profissionais, administrativos, entre outros, assim como também o é a educação de alunos procedentes das classes menos favorecidas, das comunidades indígenas, das minorias étnicas, dos analfabetos.

A leitura crítica de Lima, como se vê, vem no sentido de advertir a redução operada quando se define o bilinguismo como uma proposta educacional que se restringe somente a tornar acessível ao surdo duas línguas: a língua de sinais e o português. Trata-se de uma perspectiva que pode trazer consequências indesejáveis, pois para a pesquisadora não se trata de uma questão "de mero acesso a duas línguas no seio da sociedade, mas, principalmente, uma questão de propiciar um debate mais abrangente que proponha diretrizes para uma política educacional e linguística comprometida com a educação de minorias linguísticas apagadas nos bancos escolares”. (LIMA 2004, p.49).

No sentido de verticalizar a discussão sobre o conceito de bilinguismo no âmbito da surdez, introduzo o trabalho de Faria (2011, p.234). A pesquisadora coloca em destaque as características formais da linguagem, "condição para que se possam considerar as possibilidades de o surdo ter acesso a uma 
língua oral de escrita alfabética unicamente através da sua materialidade gráfica."

Entre as questões por ela abordadas, destaco a que diz respeito à possibilidade do surdo ter acesso a uma língua oral de escrita alfabética unicamente através de sua materialidade gráfica. Faria (2011, p.21) afirma que a língua portuguesa para surdos é um conjunto de signos visuais materializados na escrita: "para os surdos aprender a escrita significa aprender a língua portuguesa”.

A possibilidade de se adquirir uma língua exclusivamente por meio de sua escrita , como se sugere em propostas bilíngues, obriga a colocar outra questão “o que se está considerando ser o português para que se possa pensá-lo manifestado na oralidade e na escrita de forma independente, de tal maneira que possamos ser ouvintes ou surdos numa mesma língua?” (idem, p. 237). Faria (2011) assume com Hjelmslev (1943) que o Português, como forma linguística particular, é "um todo organizado que tem forma e estrutura linguística, como princípio dominante". Assumir a passagem do escrito sem passar pelo oral convoca, segundo a autora, uma reflexão sobre as especificidades formais da linguagem.

Prosseguindo com a sua reflexão, Faria (2011, p.243) coloca em pauta um ponto que merece destaque: ela afirma que pretende discutir "a natureza particular da linguagem, condição para que haja algum sentido em se propor o bilinguismo do surdo, isto é, sustentado pela possibilidade de se chegar ao Português unicamente via escrita".

Segundo Faria (2011), o problema é que, ainda que tal enfoque resolva parcialmente questões teóricas pontuais, como a relação fonema-grafema na ausência de audição, deixa-se de enfrentar questões centrais, tais como o acesso do sujeito ao funcionamento simbólico da linguagem, que não se dá a ver, ao qual não se tem acesso pela via da percepção.

Para deslocar a concepção da anterioridade de uma modalidade de linguagem dita "natural" sobre a escrita e, portanto, da ideia de representação, Faria (2011), traz as ideias centrais de Derrida (1967), apresentadas no livro "Gramatologia" e inclui, ainda, pontos relevantes da obra de Hjelmslev (1943), relativamente aos conceitos de forma e substância.

De acordo com Derrida (1973), a tese do arbitrário do signo em Saussure constitui-se num obstáculo para a distinção radical entre signo oral e signo. O estatuto do signo em Saussure é linguístico, isto é, ele não representa ideia ou coisa - "o próprio do signo é não ser imagem" (p.55). Essa tese rege as relações entre significante e significado e também entre fonema e grafema. Declara ele: “[...] Mesmo na escritura dita fonética, o significante 'gráfico' remete ao fonema através de uma rede com várias dimensões que o liga, como todo significante, a outros significantes escritos e orais, no interior de um sistema 'total', ou seja, aberto a todas as cargas de sentidos possíveis. É da possibilidade deste sistema total que é preciso partir.” (FARIA, 2011, p.245).

Também importa o que ela traz de trabalho de Hjelmslev (1943), autor que assinalava que nos estudos linguísticos seria necessária uma análise da escrita sem considerar o som. Faria (2011) parte do pressuposto de que como o surdo não dispõe da oralidade é legítimo supor que ele terá que se haver com a matéria gráfica "de maneira privilegiada para torná-la linguística", o que, certamente, não depende da 
memorização da grafia de cada palavra.

Faria (2011) retira do trabalho desse autor as ideias mais gerais implicadas no desenvolvimento da máxima de Saussure de que língua é forma e não substância, a partir da qual Hjelmslev fez inúmeras referências à linguagem dos surdos para encaminhar sua discussão no sentido de ampliar sua reflexão para além da suposição de que linguagem oral é tradução de linguagem "natural". (FARIA, op.cit., p. 247). Hjelmslev (1943), conforme assinala Faria, assume que a língua é uma entidade autônoma, implicando, assim, reconhecer que ela é constituída de dependências internas, "fatos", que não podem preceder logicamente as relações que os unem. Com isso, conclui o autor, nega-se a existência e, consequentemente, "científica de uma substância absoluta ou de uma realidade independente de relações" (Hjelmslev,1943, p. 247-248).

Dessa afirmação é possível apreender que, para Hjelmslev (1943, p.252), a língua, qualquer que seja ela, não define uma língua, pois a língua não tem sua existência ligada à substância sonora, "mas às relações que são manifestadas pela substância selecionada, seja esta sonora, gráfica, gestual ou qualquer outra". Assim, pode-se concluir, também, que o lugar da oralidade é deslocado e ela perde seu lugar de "primeira/natural" e, consequentemente, tem-se que: o que determina a fala não determina a escrita.

Faria (2011) coloca, para finalizar, uma questão de grande relevância, qual seja “de que maneira a matéria gráfica presente no texto se transforma em substância linguística, isto é, em manifestação substancial de uma forma para aquele que lê?" (FARIA, 2011, p. 250). A resposta da pesquisadora importa, e muito, para este estudo, pois ela pressupõe que haja uma mudança, não no objeto empírico o texto escrito- , mas na relação do sujeito com o texto, o que coloca em cena a ideia de captura simbólica; como propõe De Lemos (2002), definição que inverte a relação sujeito-objeto. Vejamos o que diz Faria:

Essa é uma mudança que se opera não no objeto empírico texto escrito, mas na relação que o sujeito (surdo ou ouvinte) estabelece com ele, através de um deslocamento daquilo que seus sentidos captam. Isto é, se antes o texto era simplesmente percebido em sua imagem gráfica, ele, sendo o mesmo e não o sendo mais, pode ser lido para além da decodificação "no interior de um sistema 'total', ou seja, aberto a todas as cargas de sentidos possíveis" como mencionou Derrida (1973, p. 55 apud FARIA, op.cit., p.250).

Acompanho Faria, pois considerações como essas não podem ser ignoradas; elas indicam que para pensar a aquisição de linguagem, seja ela oral ou escrita, é necessário refletir sobre o sujeito e seus modos de relação com a Língua.

\section{AQUISIÇÃO DE LINGUAGEM, BILINGUISMO E LÍNGUA MATERNA}

Quadros \& Karnoop (2004), pesquisadora de reconhecimento nacional, aborda pontos relevantes no universo da educação de surdos. Um dos muitos aspectos discutidos por ela diz respeito ao modo como se dá o processo natural de aquisição da linguagem em crianças ouvintes e crianças surdas. Em seu 
trabalho, ela coloca outras questões igualmente relevantes: 1) O que são as línguas de sinais? (2) Como são expressos os aspectos formais nessas línguas? (3) Qual o processo de aquisição da língua portuguesa em crianças surdas?

Quadros destaca a necessidade de conhecer as duas línguas envolvidas no processo educacional bilíngue dos surdos, bem como o lugar que elas ocupam nesse processo, sem descartar os aspectos linguísticos, culturais e sociais.

Como LIBRAS, na concepção de Quadros, é uma língua possível e que se faz necessário expor o surdo o mais cedo possível àquela que seria sua "língua natural". Quadros argumenta "as línguas de sinais como possível expressão da capacidade natural para a linguagem" (QUADROS \& KARNOOP, 2004, p. 22); por isso, o estudo das línguas naturais não deve se restringir às línguas faladas e que é possível incluir nele as línguas cuja modalidade é vísio-espacial.

Pereira de Castro (2006) procurou trazer à cena, de forma crítica, o tema da língua materna no interior do campo da Aquisição de Linguagem. A autora entende que assumir "a hipótese cronológica é uma resposta dada de antemão a uma questão ainda não formulada na sua complexidade, mas cuja explicitação é necessária para que se revele a posição ímpar da língua materna face às outras línguas adquiridas." (2006, p.135).

A questão da língua materna interessa a este estudo pois, no campo da surdez, conforme já indiquei, a língua de sinais, nas propostas bilíngues, é definida como língua materna do surdo. Em meu mestrado fui interrogado pela naturalidade com que se afirma nos estudos bilíngues, no campo da surdez, que a língua de sinais é a língua materna do surdo; isso porque, em $90 \%$ dos casos, ela não corresponde à língua falada pela mãe, e nem à primeira língua da criança.

Segundo Zajac (2011, p. 52), a complexidade envolvida na escrita de alunos surdos revela que não se trata de eleger uma ou outra metodologia. A partir do encontro com a proposta interacionismo e da aproximação à Psicanálise, Zajac relata que foi levada a repensar o modo de entrada na escrita e, consequentemente, a discutir o lugar do professor e a questão do método de ensino; então, entendeu que seria necessário suspender a busca de um método ideal e, também, a ideia de que o uso da LIBRAS por alunos e professores seria a condição necessária e suficiente para a apropriação do português em sua modalidade escrita. A questão é bem mais complexa, tanto do ponto de vista teórico quanto para o professor que vive os problemas cotidianos na sala de aula.

A partir do encontro com a Psicanálise, indica que a questão central "não está, exclusivamente, no fato do falante comunicar-se em duas línguas, independente do nível técnico de dominância em cada uma delas e do conhecimento de suas respectivas culturas." (ZAJAC, 2011, p.81). Acompanhando Melman (1992), ela afirma que também o aspecto subjetivo do bilinguismo deve ser considerado, o que envolve distinguir o que é saber e o que é conhecer uma língua. 
O conceito de língua materna deveria estar em cena sempre nos trabalhos que tematizam a Aquisição de Linguagem, mas é especialmente quando o foco principal diz respeito à aquisição de segunda língua que o tema aparece colocado de uma forma explicita.

Sobre a língua materna, Pereira de Castro (2006) afirma que:

Ainda que a língua materna seja definida por Lacan como uma "ocupação", este termo é em parte fruto da leitura que o autor faz com Freud, da obra de Saussure (1968). Onde exclui a possibilidade de se tomar a língua como função do sujeito falante, invertendo a relação sujeito do conhecimento-objeto ao propor que o falante "registra passivamente" a língua (Saussure, op.cit., p.30), abrindo caminho para o reconhecimento do primeiro como efeito desta (PEREIRA DE CASTRO, op. cit., p.142-143).

Ainda sobre a língua materna, Behares (1997, p.40) definiu-a, como a língua natural dos surdos, a língua de sinais devido ao "fato de que na presença dela o acesso do surdo é imediato, seja porque sua estrutura visual-manual the facilita, seja porque o fato de ser a língua de sua comunidade de referência torna possível a interação espontânea (o que não é possível em uma língua oral)". Como a primeira língua, esses autores definiram aquela que faz referência aos fatores temporais, ou seja, a que ingressa em primeiro lugar no repertório da criança, envolvendo o bebê nos primeiros tempos de vida e inscrevendoo no simbólico.

Pereira de Castro (2006) encontrou elementos que permitiram empreender uma análise que articulasse a discussão "sobre o estatuto da fala da criança e o conceito de língua materna". O que pode promover "um deslocamento teórico no conceito de língua materna, alçando-o a um lugar privilegiado para o tratamento de certas questões que afetam o campo da aquisição de linguagem" (Pereira de Castro, p.140), e, que em meu ponto de vista, são de importância fundamental para desnaturalizar o modo como a língua materna tem sido abordada nos estudos sobre a surdez. Pereira de Castro afirma que:

Milner considera língua materna fora de uma sequência - cronológica ou classificatória - de línguas: “... esta língua que usualmente chamamos materna pode-se sempre tomála por um lado que a impede de ser contada (faire nombre) entre outras línguas, de lhes ser comparada" (MILNER, 1978, apud PEREIRA DE CASTRO, 2006, p. 141). (tradução da autora ${ }^{\gamma}$.

Tal afirmação, para ela, é de natureza teórica e metodológica, pois se trata de "uma questão que, se transposta para o debate em aquisição de linguagem, deve ser pensada a partir do reconhecimento da singularidade da fala da criança" (PEREIRA DE CASTRO, op. cit., p. 141). Ela prossegue com Milner e afirma que a língua materna guarda "um traço de incomensurabilidade" que impede que ela seja incluída no lote das línguas comuns.

Ao discutir a língua materna, a partir da Psicanálise, Zajac dialogou ainda com Nunes (2004), diz

\footnotetext{
${ }^{7}$ Não ignoro que existe uma tradução do livro em questão. Entretanto, por não tê-la em mãos, traduzi o trecho citado e os outros que virão.
} 
ela:

[...] estando a criança surda impedida de ouvir a voz materna, o seu corpo passa a ser o receptáculo da fala da mãe para que seja possível a sua entrada na linguagem. Contudo, a criança não entra no barulho concomitantemente à sua entrada na fala pela linguagem. Conforme os autores, a criança é forçada a entrar na linguagem, seja pelos sons ou pelos sinais (a fala da mãe) e a sua voz ou gesto se constitui como mero fluxo de sons, balbucios, olhares amontoado de gestos, mas tudo isso se perde (como voz ou gesto) para se tornar parte da língua. Eles enfatizam que não há prejuízo à constituição do aparelho psíquico da criança pelo fato dela ser surda, já que ela convoca outros meios para que tal aconteça. Mas, as crianças natisurdas ou com surdez adquirida de forma muito precoce precisam de algum som para que o seu apelo adquira sentido. Ao abordar este ponto, Bergès e Balbo (1997) não estão se referindo a respostas da ordem da fonemática e, sim, da ordem do corpo da mãe - seus lábios, órgãos fonatórios, seu olhar, sua carícia - para responder. Desse modo, a mensagem se converterá em linguagem no olhar do filho e no corpo da mãe que interagem num jogo de comunicação. Dessa maneira, sustentam Bergès e Balbo (1997), a fonética e o lado significante (que é diferente do precedente) comporta a letra, mas esta também (quando é lida) é comportada pelo corpo. (ZAJAC, 2011, p.117-118).

Zajac afirma, também, que o conceito de captura introduzido por De Lemos, nos estudos sobre a Aquisição da Linguagem, a partir da psicanálise lacaniana, obriga a suspender a ideia que se tem de "língua materna", quando estão em pauta questões relacionadas ao modo de relação do surdo com o simbólico (ZAJAC, 2011, p. 118). E que se "pensarmos na língua materna como causa singular do sujeito, matéria fundadora de seu psiquismo, podemos redimensionar a questão da relação do sujeito com a escrita.” (ZAJAC, 2001, p.118).

A relação do surdo com a escrita envolve uma questão mais profunda e complexa. Sobre isso Zajac afirma que é importante ressaltar que para pensar na relação do surdo com a escrita, não se pode esquecer que quando o surdo chega à escola, ele já percorreu uma longa trajetória que envolve o diagnóstico, a escolha do tratamento e, especialmente, o modo como os pais se enlaçaram à criança.

Tais acontecimentos se inscrevem no corpo do surdo e não podem ser deixados de lado, como discute Nunes (2004), ao fazer uma leitura crítica dos estudos sobre a escrita do surdo. Nessa leitura, ela assinala que o "fracasso" dessas crianças se dá tanto não somente nas escolas comuns, [...] mas, também, nas escolas especiais para surdos, como se pode notar nas pesquisas de Góes (1996) e Souza (1996). Tentando compreender o fenômeno, Nunes (2004) arrisca a seguinte hipótese: apesar das inúmeras tentativas, "não há a incidência efetiva de uma língua sobre os alunos, mas de recursos comunicativos múltiplos, e o resultado pode ser língua nenhuma." (NUNES, 2004:39). A autora encerra esse tópico com as seguintes considerações: se existe possibilidade de transmissão, essa é da língua e na língua em que professores e alunos circulam. Como afirma Vorcaro (1999): a transmissão é simbólica, portanto, está absolutamente subordinada ao que a língua põe em funcionamento. Assim, o código criado para funcionar como instrumento de comunicação, acabaria por manter a dificuldade dos alunos em relação à inscrição no laço social, restringindo-o à poderosa lei do semelhante, lei encarnada unívoca e impositiva, em que eles só podem se alocar como objetos de sua incidência (NUNES, 2004:39 apud ZAJAC, 20111 p.78).

Revista Lumen, v. 4, nº 7, Jan./Jun. - 2019 - ISSN: 2447-8717 
De acordo com Zajac, acompanhando a conclusão a que se chega, a partir das pesquisas sobre a escrita do surdo é que os fracassos: "são determinados não pelo déficit auditivo, mas pelos efeitos da surdez na relação com a alteridade que com ela se confronta através daqueles que lhe servem de suporte: pais, professores, profissionais etc.” (ZAJAC, 2011. p.81).

\section{CONSIDERAÇÕES FINAIS}

Minha inquietação, como professor de língua portuguesa para surdos, conforme assinalei na

introdução deste artigo, diz respeito ao desejo de encontrar um caminho que pudesse produzir mudanças no modo como meus alunos surdos se relacionam com a língua portuguesa escrita e não fazer apenas sensacionalismo da língua ou do surdo, da surdez.

A ideia de que a linguagem pode ser ensinada ainda impera na maior parte das propostas educacionais para surdos. Assim, Aquisição de Linguagem é vista como indiquei: tão somente por um viés pedagógico.

Os trabalhos visitados permitiram questionar, uma vez mais, o modo irrefletido com o qual o conceito de língua materna é tratado no campo da surdez. A autora considera que a língua de sinais pode ser entendida como materna somente para crianças surdas, filhas de pais surdos. A suposta naturalidade na aquisição da língua de sinais, assim como a ideia de que há relação entre uma língua natural e a escrita é da ordem da representação.

Vale lembrar que, na questão da surdez, estão em jogo não apenas duas línguas, mas duas modalidades de língua - e isso importa muito na escrita do surdo.

Encerro afirmando que a escrita de meus alunos surdos traz a marca do modo como se deu a estruturação subjetiva da linguagem, e que ela não tem relação direta com a surdez e nem com abordagens pedagógicas. Quero com isso dizer que a direção que pode permitir um avanço no sentido de apreender o modo enigmático de presença de crianças surdas na escrita é aquela que leva, às últimas consequências, a solidariedade entre estruturação da linguagem e estruturação subjetiva. Somente assim a questão do método de ensino, que interessa a todo professor, pode vir a ser deslocado em favor da ideia de transmissão, mas essa é uma questão para outro tempo.

\section{REFERÊNCIAS}

ANDRADE, L. Owvir e escutar na constituição da clínica de linguagem. 2003. Tese (Doutorado em Linguística Aplicada e Estudos da Linguagem) - Pontifícia Universidade Católica, São Paulo, 2003.

ARANTES, L. Diagnóstico e Clínica de Linguagem. 2001. Tese (Doutorado em Linguística Aplicada e Estudos da Linguagem) - Pontifícia Universidade Católica, São Paulo, 2001. 
BIZIO, L. Considerações sobre o ensino de lingua portuguesa para surdos. 2008. Dissertação (Mestrado em Linguística Aplicada) - Pontifícia Universidade Católica, São Paulo, 2008.

BEHARES, L. E. A língua materna dos surdos. Revista Espaço/INES, Rio de Janeiro, ano IV, n. 6, p.4049, 1997.

BORGES, S. O quebra-cabeça: a alfabetização depois de Lacan. Goiânia: Universidade Católica de Goiás, 2006.

BRASIL. Decreto $n^{0}$ 5.626, de 22 de dezembro de 2005. Regulamenta a Lei no 10.436, de 24 de abril de 2002, que dispõe sobre a Língua Brasileira de Sinais - LIBRAS, e o art. 18 da Lei no 10.098, de 19 de dezembro de 2000. Disponível em: http://www.planalto.gov.br/ccivil_03/_Ato20042006/2005/Decreto/D5626.htm. Acesso em: 25/10/2019.

BRASIL. Lei $n^{\circ}$ 10.436, de 24 de abril de 2002. Dispõe sobre a Língua Brasileira de Sinais - LIBRAS e dá outras providências. Disponível em: http://www.planalto.gov.br/ccivil_03/leis/2002/110436.htm. Acesso em: 25/10/2019.

BRASIL. Lei $n^{\circ}$ 10.098, de 19 de dezembro de 2000. Estabelece normas gerais e critérios básicos para a promoção da acessibilidade das pessoas portadoras de deficiência ou com mobilidade reduzida, e dá outras providências. Disponível em: http://www.planalto.gov.br/ccivil_03/leis/110098.htm. Acesso em: $25 / 10 / 2019$.

CARVALHO, G.M.M. O erro em aquisição de linguagem: um impasse. In.: M.F. Lier-DeVitto \& L. Arantes. Aquisição, Patologias e Clínica de Linguagem São Paulo: EDUC/ PUC-SP, 2006. p.63-78.

CERQUEIRA, C. Clínica de Linguagem: interrogações e pontuações sobre retardo de linguagem a partir do atendimento de uma criança. 2006. Dissertação (Mestrado em Linguística Aplicada e Estudos da Linguagem) - Pontifícia Universidade Católica, São Paulo, 2006.

DERRIDA, Jacques. (1967) Gramatologia. Tradução: Miriam Schnaiderman e Renato Janini Ribeiro. São Paulo: Perspectiva, 1973.

FARIA, N. R. B. Forma e substância na linguagem: reflexões sobre o bilinguismo surdo. Revista Leitura, Maceió, n.47, p.233-254, 2011.

GUADAGNOLI, C.F. Considerações sobre a Fala-Leitura-Escrita e Efeitos Clínicos no Atendimento de Afásicos. 2007. Dissertação (Mestrado em Linguística Aplicada e Estudos da Linguagem) - Pontifícia Universidade Católica, São Paulo, 2007.

HJELMSLEV, L. (1943) Prolegômenos de uma teoria de Linguagem. São Paulo: Perspectiva, 1975.

DE LEMOS, C.T.G. Sobre a Aquisição da Linguagem e seu dilema (pecado) original. Boletim de Abralin. Recife, vol.3, p.3-16, 1982.

LEMOS, C.T.G. de. A criança e o linguista: modos de habitar a língua? (The child and the linguist: ways of inhabiting language?), ESTUDOS LINGUÍSTICOS, São Paulo, 43 (2): p. 954-964, maio-ago 2014. 
LIER-DeVITTO, M. F. Falas sintomáticas: um problema antigo, uma questão contemporânea. In: FREIRE, M.; ABRAHÃO, M. H.; BARCELOS, A. M. P. (org.). Linguistica e contemporaneidade. Campinas: Pontes, 2005. p.317-327.

LIER-DeVITTO, M. F.; ANDRADE, L. Considerações sobre a interpretação de escritas sintomáticas de crianças. Estilos da Clínica, São Paulo, v. 13, n. 24, p. 54-71, 2008.

LIER-DeVITTO, M. F., ARANTES, L. Aquisição, patologias e clinica de linguagem. São Paulo, EDUC, FAPESP, 2006

Falas sintomáticas: fora do tempo, fora do lugar. Cadernos de Estudos Linguísticos, UNICAMP,

Campinas, v.47, $\mathrm{n}^{\circ} 1-2, \mathrm{p} .143-150,2005$.

LIMA, M. S. C. Surder, Bilinguismo e Inclusão: entre o dito, o pretendido e o feito. 2004. Tese (Doutorado em Linguística Aplicada). - Instituto de Estudos da Linguagem, Universidade Estadual de Campinas, Campinas/SP, 2004.

NUNES, L.M. A escrita em gesto: um caso de surdez: 2004. Tese (Doutorado em Linguística) - Instituto de Estudos da Linguagem, Universidade Estadual de Campinas, Campinas/SP, 2004.

PEREIRA DE CASTRO, M.F. Sobre o (im)possível esquecimento da língua materna, In: Lier-De Vitto, M.F.; ARANTES, L. Aquisição, Patologias e Clínica de Linguagem. EDUC/SP, 2006. p.116-131.

PIRES, V. L. Pontos de conflito na relação criança-escrita e seus efeitos heterogêneos: rasuras, reformulações, recomposições textuais. 2015. Tese (Doutorado em Linguística Aplicada) - Pontifícia Universidade Católica, São Paulo, 2015.

QUADROS, R. M.; KARNOPP, L. B. Lingua de Sinais Brasileira: estudos linguísticos. Artes Médicas, Porto Alegre, 2004.

SANTOS, R.V. Impasses na relação do aluno com a escrita no Ensino Fundamental. 2008. Dissertação (Mestrado em Linguística) - Pontifícia Universidade Católica, São Paulo, 2008.

SAUSSURE, F. (1916) Curso de Linguística Geral. BALLY, Charles; SECHEHAYE, Albert (org.). Tradução Antônio Chelini, José Paulo Paes, Izidoro Blikstein. 30 ed. São Paulo: Editor Pensamento Cultrix, 1989.

ZAJAC, S. Questões sobre o ensino de lingua portuguesa para surdos: um novo olhar, novas perspectivas. 2011. Tese (Doutorado em Linguística) - Pontifícia Universidade Católica, São Paulo, 2011. 